November is not a good birth-month, being le mois des morts. If a child sucks his finger, the habit is curable; but, if he sucks his thumb, nothing will break him of it, and it is of no use trying.

A girl who goes about with her dress not properly fastened, e.g. unhooked at the back, will lose her lover. (Just such another bit of popular morality as the second "marriage omen" in the last set of notes.)

E. H. and H. J. Rose.

\title{
Customs at Death among the Manipuris and Cognate Clans.
}

All deaths which are not in the ordinary course of nature are considered likely to have evil effects either on the community or on the near relations of the deceased. This belief is found among all the inhabitants of the hill tracts of Assam, and there are many interesting points with reference to it which would repay investigation, but in this note I only propose to deal with the deaths of infants and deaths in childbirth. Such deaths are generally classed as abnormal, and necessitate the performance of some ceremony to remove the evil consequences which are thought likely to ensue.

The spirits of infants which die under three years of age are considered by the Manipuris to be extremely malicious, and, should any one tread on the grave of such a child, he would certainly get some disease of the eyes or of the feet. Such spirits are also always on the look-out for an opportunity to become reincarnated, and therefore steps have to be taken to avoid this, for it is thought that the child in which the spirit is born again will also die young. As is only natural, the spirit is more likely to re-enter the womb of the mother of the dead baby than that of any other woman, and therefore the parents perform the ceremonies described below to avert such a misfortune.

The spirits of male children dying in infancy are called Suren, and those of females Apumbi. In order to prevent them from 
injuring passers-by, their bodies are buried in remote spots where people do not go frequently, - often in deep graves close to the water's edge on a river bank. The Maiba, or priest of the ancient gods of the country, buries with the corpse some well-roasted peas, saying,- "When these peas spring up you may return, and not before." In Andro, a village inhabited by people who have not yet been perverted to Hinduism, the Maiba takes a stone and a little cotton wool, and, having put the stone into the right, and the wool into the left, hand of the dead child, he throws them into some water, saying,- "You are bad; do not return till this stone floats and this cotton sinks." 1

The burial takes place on the day of the death, and three days later the Lai-yu-pal ${ }^{2}$ ceremony is performed. The Maiba takes a bunch of plantains, and, commencing from one end, says chäng (alive) to the first, and si (dead) to the second, and so on. If the word si falls on the last fruit, the bunch is suitable; otherwise it is rejected, and the experiment repeated till a suitable one is found. This bunch is then placed in the verandah of the house, and beside it are placed two pieces of plantain leaf cut into a circular form, on one of which is placed a little betel nut, and on the other a fruit called hei-ruk. If the child be a boy, a puggri, loin. cloth, and muslin shawl are placed beside the other offerings; if the infant be a girl, a petticoat and the muslin shawl suffice. The Maiba invokes the spirit of the child, saying,- "We have given you all things. Go and do not return." The articles then pass into the possession of the Maiba. Three months later a complicated ceremony known as Suren thingatpa is performed. The following articles are collected and placed on a winnowing-fan,an earthen cup containing a duck's egg and rice flour, a second cup full of parched rice, a bunch of plantains terminating in chäng and two bunches terminating in si, two circular pieces of plantain leaves with betel nut and fruit on them, and six cloths. The

\footnotetext{
'Should the mother die before giving birth, the foetus is removed and buried as above described.

${ }^{8}$ This name is a survival of pre-Hindu days. To this day the Nãga before drinking pours a little of his $y u$ (rice beer) on to the ground as an offering to the lai or god. The Manipuris, having become strict Vaishnavas, omit the $y u$, while keeping the name.
} 
plantains are placed on the top of the third cloth, and the other things are laid over them. If the parents are poor, a puggri, muslin shawl, and either a loincloth or a petticoat may be substituted for the cloths. The winnowing-fan with its contents is now placed on one side, and the following articles are collected in the verandah, - a handkerchief, a plantain leaf, a bunch of plantains ending in chang, a betel nut which has begun to sprout, one big and seven small pan leaves, a lemon or some sort of lime, two circular pieces of plantain leaves on which pan and betel nut and some fruit are placed, and a candle made of beeswax. These being all collected in the verandah, the ceremony commences about six or seven in the evening. The Maiba faces Kobru, a high hill at the northern end of the valley and the abode of a very powerful Umang-lai or forest god, who is called the guardian of the north, and recites a prayer to Guru-sidaba, who is the chief of the seven gods of the stars. The goods collected in the verandah, having been offered to the god, are removed, and become the property of his minister the Maiba.

The next stage in the proceedings commences with a small portion of the eatables collected on the winnowing-fan being brought and placed on a handkerchief in the north-east corner of the verandah, while the Maiba addresses Lamjasara lathokpa. "Here we offer you your share. Do not disturb our worship." [Lamjasara lathokpa is a malevolent spirit, who has no home, and so wanders about troubling mankind.] All preliminaries being accomplished, the actual Suren thingatpa ceremony commences by the parents, dressed in their best clothes, taking up their position in the north-east corner of the yard, the Maiba standing on their right holding the winnowing-fan with all the articles on it. The whole party faces Kobru. The Maiba passes the winnowingfan to the father, and the parents hold it over their heads, moving it up and down while the Maiba prays that the Suren will be satisfied and go to Guru.sidaba, and not return and trouble people. This over, the winnowing-fan is returned to the Maiba, who takes possession of its contents. The parents, relieved of care as to the Suren, dance back to the house. If they are desirous of more children, the Maiba follows them and gives the father a lime, which he has previously offered to Guru-sidaba, 
saying,-" Here is a child that Guru-sidaba has sent to you." The father takes it, and hands it to his wife, who wraps it in her cloth and nurses it as if it were a baby. This lime is kept very carefully in some secret place. The offering to Lamjasara lathokpa is left until the morning, and then thrown away.

Should an outbreak of sickness cause people to think that some Suren has not been appeased, enquiries are made, and, if the offending parents can be found, they are compelled to carry out the ceremony. If the enquiries lead to nothing, the ceremonies are performed by public subscription among the members of the Sagei (i.e. those who can trace their descent back to a common ancestor). From a note supplied to me by the Rev. IV. Pettigrew, who has been many years working among the Tangkhuls (a clan of some 26,000 souls inhabiting the hills between the valley of Manipur and the Chindwin), we learn that the bodies of children dying in infancy are buried promiscuously in shallow graves, and they are not represented in the annual ceremony in bonour of those who have died during the year. Their spirits are supposed not to become honey bees, like those of other folk, but house flies, and to live on the refuse of other spirits' plates in Kazai-ram, the abode of the dead. A piece of a shrub called mangrahai, (a species of cock sorrel,) is placed in the hand of the infant before burial, in order that the little one may suck it and appease its hunger on the way to Kazai-ram. Among the Kabuis, a tribe inhabiting the hills to the west of the Manipur valley, the bodies of such infants are buried behind the house, without ceremony, other burials taking place in front. The village is unclean for five days, during which no one may go out. Among the Shans in the Upper Chindwin valley, if the youngest child of a family dies while still an infant, it is buried without any ceremony. After death the corpse must not be laid down, but must be carried in the arms of some relative. A week later the mother squeezes some of her milk on to the place where the child used to sleep, and some milk and boiled rice is sent to the phongyis (priests) in place of the usual funeral feast. ${ }^{3}$ Among the Lusheis,

'Should a woman die before childbirth, the Shans, like the people of Andro, remove the foetus and bury it separately, lest the spirit should trouble that of the mother in a future state. 
a first-born child dying within a year of its birth is termed hlamzuih (hlam, afterbirth, and zuih, to follow), and is buried without any ceremony under the house. The spirits of such children cannot be shot at by Pupawla, the dreaded archer whose house is at the junction of the seven roads to Mi-thi-khua, the dead men's village, whence he shoots with his pellet bow at all poor souls hurrying by. In Marām, a Naga village to the north of the Manipur valley, the corpse of a child dying within ten days of its birth is buried at the foot of the centre post of the house, instead of outside. The Kolhen, another small tribe living near the Manipur valley, also fix ten days as the unlucky period, and children dying within it are buried under the eaves of the house. Among the Ronte, children dying within a year of birth are buried without ceremony to the east of the village, whereas the regular cemetery is to the west. It will be seen that, though all these clans treat such deaths as abnormal, and bury the bodies of such children in a manner different to those of persons dying in the ordinary way, it is only among the Manipuris, the people of Andro, the Shans, and the Ronte that the difference in procedure denotes a fear of the spirit of the dead child. All the other clans, while observing no ceremony, bury the body either in or near the house, as if to encourage the return of the spirit. The absence of ceremony may be due to a belief that the spirit which sojourned so short a time has hardly acquired a distinct personality, which would account for the omission of all reference to such spirits at the Tangkhul annual ceremony in honour of the dead.

We will next consider the cases in which women die in childbirth or soon after. Among the Kabui a death occurring within two months of the birth is classed as "unlucky." Among the people of Andro a death occurring before the removal of the afterbirth is counted as an unnatural death. In Phayeng, a village closely allied to Andro, deaths occurring on the day of the birth are unnatural. In other clans the periods are less clearly defined, but in all clans such deaths are considered unlucky, and there is a general belief that it is possible, so to speak, to catch the disease from the corpse, and therefore, in nearly every clan, the funeral has to be carried out by very old men and women. Other precautions are taken to remove the "infection." Among 
the Kabui, all the woman's clothing and all cloths which she may have woven, even if they are in possession of others, are thrown away, the body is taken out of the house through the back door, and the back portion of the house is pulled down. The husband is not allowed to eat the flesh of any animal that has died, nor any vegetables unless he cooks them himself, until the annual festival which marks the close of the year. The village itself is closed for five days, and no one may go out ; if any enter, they cannot leave till the fifth day is completed. In some villages, no thread may be dyed red or black for five years; in others, the prohibition is only for the current year. In Marām the whole house is demolished. Among the Tangkhuls, Mr. Pettigrew notes that the body must be buried by very old men and women, and that young folks are even prohibited from eating any of the meat either in the funeral feast or at the annual ceremony in honour of the dead, for fear that they themselves should die in the same way, or become barren or impotent. In most clans some purifying ceremonies have to be observed either by the whole village or by the family of the deceased. In Andro, the whole Sagei is unclean until the following ceremony has been performed on a day selected by the Maiba. The whole Sagei having assembled, two fowls are produced and laid on the ground, with their legs tied, so that they cannot move away. Each member of the Sagei then takes a mouthful of water, and, stepping over one fowl, blows the water over the other. After each has done this three times, all receive a little ginger, haimang (a jungle fruit), salt, and pepper, after which they are clean. The Maiba receives a black dog, a goat, and a fowl. None of the Sagei may eat the flesh of these animals. The corpse is burnt in the ordinary manner, but at Phayeng the corpse is taken to a special place outside the village, where it is burnt with some paddy, vegetables, and the body of a goat that is killed beside the funeral pile. Among the Manipuris a very elaborate ceremony has to be performed to remove the evil influence from the husband. The various articles having been arranged in the yard of the house, as shown in the following diagram,- 


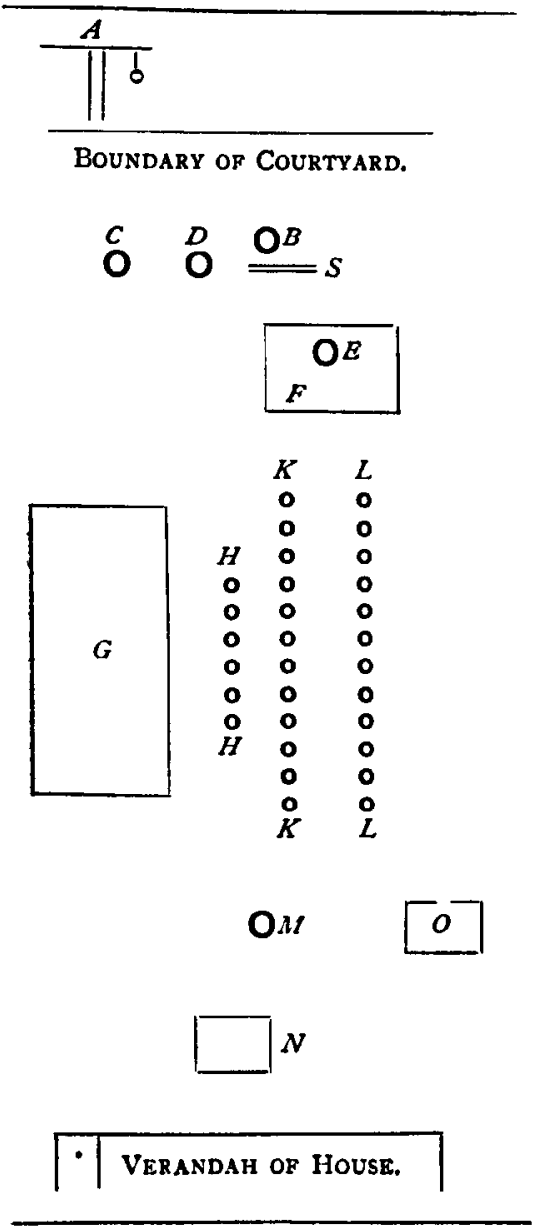

A. A tree or post on which is hung a packet of all sorts of eatables wrapped up in leaves.

B. A branch of the Nongleisang tree planted in the ground.

C. Basket of paddy.

$D$. Basket of rice.

S. Seng-gam, two upright reeds supporting a third from which depends a black cloth containing twenty pice (copper coins), the whole being covered by a white cloth.

$E$. A winnowing fan, on $F$, a nat.

$G$. Three cloths laid on the ground, and on them a bunch of plantains, covered by three more cloths ; said to represent the corpse.

$H-H$. Pan and betel nut.

$K-K$. Twelve kegam, cups full of rice with a lime on the top of each.

$L-L$. Twelve chapu, earthen pots full of rice with a lime on the top of each.

M. A pot of water.

N. Maiba's seat.

O. Lei-hul, flowers offered to Senamahi, household god.

the sister of the husband brings some flowers and a little rice. Five discs of local salt are hung up along the front of the verandah, and after the ceremony these are thrown away outside the village, where cows are likely to eat them; this is to remove bad luck, and prevent the recurrence of such a catastrophe. The Maiba now takes his seat behind the water pot, in which, while muttering charms, he moistens a bunch of leaves. The floor of 
the house is smeared with fresh cow-dung, and the hearth is cleaned and sprinkled with water by the Maiba, who enters with three other men. He takes a little earth from the hearth, and places it in a leaf held by one of his companions. They then all four walk around the hearth thrice, and then go out. The old earth is thrown away, and some fresh is obtained and put into the place on the hearth whence the old earth was taken. After this the husband is seated in the yard in front of the Maiba, and is sprinkled by him with the holy water, and then the husband's sister presents the Maiba with rice and vegetables and some money. All the articles laid out are removed to the Maiba's house, except the bag of pice, which is left hanging from the Seng-gam. The Maiba walks off towards his house, holding his hands behind his back, and the husband takes the black cloth with the pice inside it and, running after the Maiba, places it in his hands, saying,-- "You have forgotten something." The Maiba must go straight on without looking round, and thus all the ill-luck is removed.

Among the Shans of the Upper Chindwin valley, the woman's corpse is buried in the usual way, but the husband has to go through a purification ceremony. Immediately after the burial he changes into ragged clothes beside the grave, and feigns madness. The villagers pelt him with stones, and he flies from them to the river and plunges in. On emerging he dresses in new clothes, and returns cleansed. The house also has to be purified. In these cases also we find indications of two prevailing ideas. In the two last cases the house and the husband are specially purified, the corpse being disposed of in the ordinary way. At Andro, the evil influence spreads to the whole of the Sagei, but it appears to be independent of the corpse. In the other class of cases the evil influence seems to be specially attached to the body and clothing of the deceased, and in some cases to the house also. The Kabuis seem to hold both theories, as the prohibition placed on the husband eating certain articles is evidently meant to counteract the malign influence to which he is supposed to be particularly subject, and the closing of the village for five days, and the tabu placed on dyeing thread, show that the whole community is also considered in danger, while the "infection" clings. 
to the clothing of the deceased, and is communicable even by cloths which she has woven long before.

All the clans to which I have referred, except the Shans, are very closely connected, and one would have expected to have found greater uniformity in their ideas. As yet I have no explanation to offer of the cause of the differences pointed out, but perhaps some reader may be able to suggest one.

J. Shakespear.

\section{ARMENIAN RiddLES.}

AT social gatherings amongst Armenians, proverbs and riddles are sometimes repeated for the entertainment of the company, and the following are translations, with answers, of favourite riddles used for such a purpose :

I. I tie it; it goes a-roaming;

I loose it; it stays a-homing. (A shoe.)

2. A dark house; a snug sleep. (The grave.)

3. There's a deep, deep well ;

All there is betwixt heaven and hell

Falls therein. (The ear.)

4. The more $I$ hew it, the longer it grows;

The more I smooth it, the thicker it grows. ( $A$ well.)

5. I grasp it; I cast it ;

It dieth a year; then again doth appear. (Wheat sowing.)

6. Unstrung pearls; unwound thread;

The Lord threads them; man unthreads them.

7. Flint above; no rock is it;

(A pomegranate.)

Grass it eats ; no sheep is it ;

Eggs it lays; no fowl is it. (A turtle.)

8. A snow-white field I own;

With my hand it is sown;

With my lips it is mown. (A letter.) 